Research Journal of Applied Sciences 7 (3): 138-145, 2012

ISSN: $1815-932 \mathrm{X}$

(C) Medwell Journals, 2012

\title{
Financial Crisis and the New Data on the Wood Pellet Heating: Case Study of Greece
}

\author{
Jacob. G. Fantidis, Dimitrios V. Bandekas, Nick Vordos, \\ Costas Potolias and Kostas Karakoulidis \\ Department of Electrical Engineering, Kavala Institute of Technology, \\ P.O. Box 65 404, St. Lukas, Greece
}

\begin{abstract}
The financial and economic crisis in Greece has changed the balance between the fossil heating fuels and the biomass. Biomass is a renewable energy source and replaces fossil fuels in existing heat devices. The aim of this study is to investigate the financial feasibility of a Biomass Heating System in Greece. The RETScreen Software was used in order to predict the financial viability and the green house gas emissions reductions in cities which are placed in areas with very different climatic conditions.
\end{abstract}

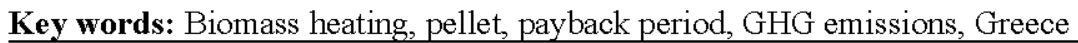

\section{INTRODUCTION}

Rapid depletion of fossil fuel resources, increasing of fuel prices such as oil or gas, climate effects, air quality issues and energy dependency concerns have been the motivations to promote the use of renewable energy in several countries. Biomass is a renewable energy source and especially in small and medium scale heat production a change from fossil fuels to biomass is reasonable and economically feasible. Another characteristic of the biomass is that the socio-economic effects take place in the less industrialized regions. In terms of employment according to the EurObserv'ER only in the European Union the workforce is approximately 300,000 (Mediavilla et al., 2009; Verma et al., 2011).

One of the fastest growing biomass fuel formats are a wood pellets. Their success can be explained since they are a condensed uniformly sized form of biomass energy, making them easier to handle, transport and store than many other biomass fuels. Pellets have high energy content and their price is stable compared to fossil fuels. Pellet heating technology is also relatively simple, minimizing operation and maintenance requirements. Last but not least pellets heating systems can be easy to plan and install while providing significant local economic and environmental benefits. Today, wood pellet boilers/stoves have become a successful fuel for small and medium heating plants, especially in countries from the North and the Centre of Europe (Finland, Sweden, Switzerland, Austria and Germany) (EurObserv'ER, 2011), Wiinikka and Gebart (2004). In Greece, there are a large number of small heating units operating with heating diesel. However, the financial and economic crisis brought new taxes in the Greek citizens and in the fossil heating fuels. With the new financial data the major part of these units expects be replaced to ones operating on solid biomass fuels in the near future. The objectives of this research are to evaluate this replacement. The economic analysis and the environmental considerations calculated using the RETScreen Software. The RETScreen Clean Energy Project Analysis Software (RETScreen International, 2010) is an advanced mathematical model specifically aimed at facilitating pre-feasibility and feasibility analysis of clean energy technologies.

\section{RETSCREEN SOFTWARE}

The RETScreen Software Biomass Heating Project Model was used to perform the economics feasibility and emission reductions (RETScreen International, 2010). The RETScreen Model can be used to evaluate biomass heating projects from larger scale developments for clusters of buildings to individual building applications anywhere in the world. The software contains six worksheets (energy model, solar resource and heating load calculation, cost analysis, Greenhouse Gas Emission Reduction Analysis (GHG Analysis), financial summary and sensitivity and risk analysis). The project takes for granted a typical solid fuels boiler in order to calculate the financial viability and the emission reduction due to the biomass (pellet) boiler. The RETScreen makes use of heating degree-days to calculate the building (or buildings) heating requirements. Heating degree-days are

Corresponding Author: Dimitrios V. Bandekas, Department of Electrical Engineering, Kavala Institute of Technology, P.O. Box 65 404, St. Lukas, Greece 
defined as the difference between a set temperature (in Greece $18^{\circ} \mathrm{C}$ ) and the average daily temperature and described by the equation:

$$
\mathrm{DD}_{\mathrm{i}}=\sum_{\mathrm{k}=1}^{\mathrm{N}_{\mathrm{i}}}\left(\mathrm{T}_{\mathrm{set}}-\mathrm{T}_{\mathrm{a}, \mathrm{k}}\right)
$$

Where:

$\mathrm{DD}_{\mathrm{i}}=$ The monthly degree-days for month $\mathrm{i}$

$\mathrm{N}_{\mathrm{i}}=$ The number of days in month $\mathrm{i}$

$\mathrm{T}_{\text {set }}=$ The set temperature

$\mathrm{T}_{\mathrm{a}, \mathrm{k}}=$ The average daily temperature for day $\mathrm{k}$ of month i

The annual degree-days, DD are calculated by adding the monthly degree-days. The RETScreen Biomass Heating Project Model allows the user to include domestic hot water as part of the energy demand met by the heating system. RETScreen calculates the equivalent degree-days for domestic hot water demand $\left(\mathrm{DD}_{\mathrm{DHW}}\right)$ using the following equation:

$$
\mathrm{DD}_{\mathrm{DHW}}=\frac{\mathrm{d}}{(1-\mathrm{d})} \mathrm{DD}
$$

According to the RETScreen manual the hot water demand is supposed steady throughout the year and is expressed by the user as a fraction $d$ of the annual total demand (in this project is set to
20\%) (Clean Energy Project Analysis, RETScreen ${ }^{\circledR}$ Engineering and Cases Textbook in 2005) (ASHRAE, 2005).

\section{CASE STUDY (GREECE)}

Climate of Greece: The climate of Greece is primarily Mediterranean. Though, due to the country's unique geography, Greece has a significant range of micro climates and considerable local variations. Average annual temperature in Greece ranges from +10 to $+19.7^{\circ} \mathrm{C}$. However, since Greece is commonly a mountainous country, real average temperatures vary considerably from region to region. According to the heating Degree-Days (DD) the Greece can be divided in 4 climatic zones (Fig. 1) (Technical Chamber of Greece, 2010). In the Zone A, the annual DD are between 450-1000. During the Summer, the weather is almost always sunny and dry, Winters are wet and the snowfalls occur rarely if ever. Every year at least 6 months (May to October) there aren't heating requirements. The Zone $\mathrm{B}$ has similar climate with hot dry Summers and heat waves can occur. Winters are mild and wet and any snow that falls does not last too long. The typical range of values for yearly DD is $1000-1500$. In the climatic Zone $\mathrm{C}$, the climate is wetter than the Zone $\mathrm{B}$ and has cooler Winters and not so hot Summers. There are more snowfalls and the annual DD range from 1500 up to 2000. In the Zone D the Winter is harsh with abundant snowfalls while the summers are cool with frequent

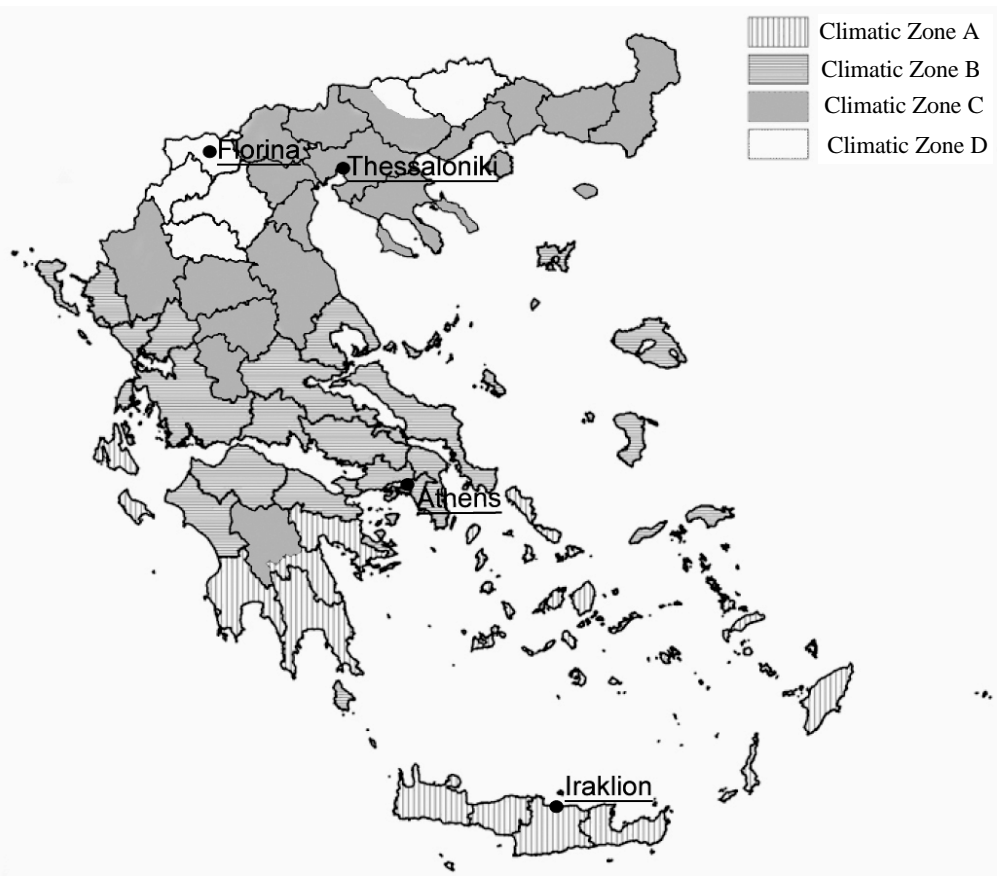

Fig. 1: Climatic zones in Greece 
thunderstorms. In these areas the climate often characterized as Alpine Mediterranean. The heating requirements (2000-2700 DD) in terms of the DD are comparable to many areas from the central Europe (e.g., Milano 2176, Torino 2459, London/Heathrow 2481, Lugano 2329, Freiburg 2678, Paris/Le Bourget 2368) (RETScreen International, 2010).

Description of assignment: Financial and economic crisis in Greece has changed the data on the field of the heating cost. On October 2009 the heating diesel price in Greece was approximately $0.56 € \mathrm{~L}^{-1}$, however with rising fossil fuel prices and mainly with the new taxes today (May 2011) the heating diesel price costs $>0.93 € \mathrm{~L}^{-1}$. Coinstantaneously, new taxes and the slashing of salaries has changed the standard of living for many people in Greece. For these reasons many building owners search for alternatives to fossil heating fuels. Biomass pellet burner Thokas- $\Theta 30$ was selected as a typical industry available burner. This, wood-fired boiler is manufactured in the Greece and provides a capacity of $30000 \mathrm{kcal}$ $(12.9 \mathrm{~kW})$ with a seasonal efficiency of $90 \%$. The pellet burner which incorporates a 2001 storage silo will replace the diesel one. Technical and financial information of the boiler are shown in Table 1 .

In the present study four cities (Iraklion, Athens, Thessaloniki and Florina), representative samples from

Table 1: Technical and financial information of the biomass boiler

\begin{tabular}{ll}
\hline ParameterS & Value \\
\hline Rated capacity $(\mathrm{kW})$ & 12.9 \\
Dimensions W x H x D (cm) & $169 \times 159 \times 110$ \\
Chimney diameter (mm) & $\varphi 20$ \\
Water supply (in) & $11 / 4$ \\
Efficiency (\%) & 90 \\
Initial costs (€) & 2500 \\
Contingencies & $3 \%$ \\
O and M costs $(€)$ & 50 \\
\hline
\end{tabular}

each climatic zone are considered. In all circumstances, heated floor area for building was $90 \mathrm{~m}^{2}$. The performance from a pellet boiler is strongly dependent on the climatic conditions and accurate weather data in a targeted location is essential. The required weather data for each of the four cities were obtained from the TEE-TCG (Technical Chamber of Greece) (Technical Chamber of Greece, 2010).

Iraklion is located in the first climatic zone of Greece. With population around of 130000 people is the biggest tower in Crete which is the biggest island of Greece. Athens which is located in the second climatic zone is the capital of Greece and with population 4 million people is one of the biggest cities in the Europe. Thessaloniki is the second largest city in Greece ( 1 million people population) and is positioned in the third climatic zone. Finally, Florina is a small city with 15000 people which is placed in the North Greece. Florina is one of the coldest areas in Greece with annual heating DD $>2500$.

The long-term seasonal variation of air temperatures at 4 locations is shown in Fig. 2. The corresponding heating DD per month for each of the 4 consider cities are shown in Fig. 3. As it can be seen from these figures during the months June to September there aren't heating requirements in any part of the Greece. The heating load for building with medium insulation is set to $70 \mathrm{~W} \mathrm{~m}^{-2}$ for the city of Iraklion. The same parameter has value $80 \mathrm{~W} \mathrm{~m}^{-2}$ for Athens, $90 \mathrm{~W} \mathrm{~m}^{-2}$ for Thessaloniki and $100 \mathrm{~W} \mathrm{~m}^{-2}$ for Florina (RETScreen International, 2005).

Financial data: With intention to evaluate the saving cost current diesel price has been taken into consideration for each of the 4 cities. According to the data from Hellenic ministery of development. Iraklion has the most expensive heating diesel oil price tag about $0.978 € \mathrm{~L}^{-1}$, mainly

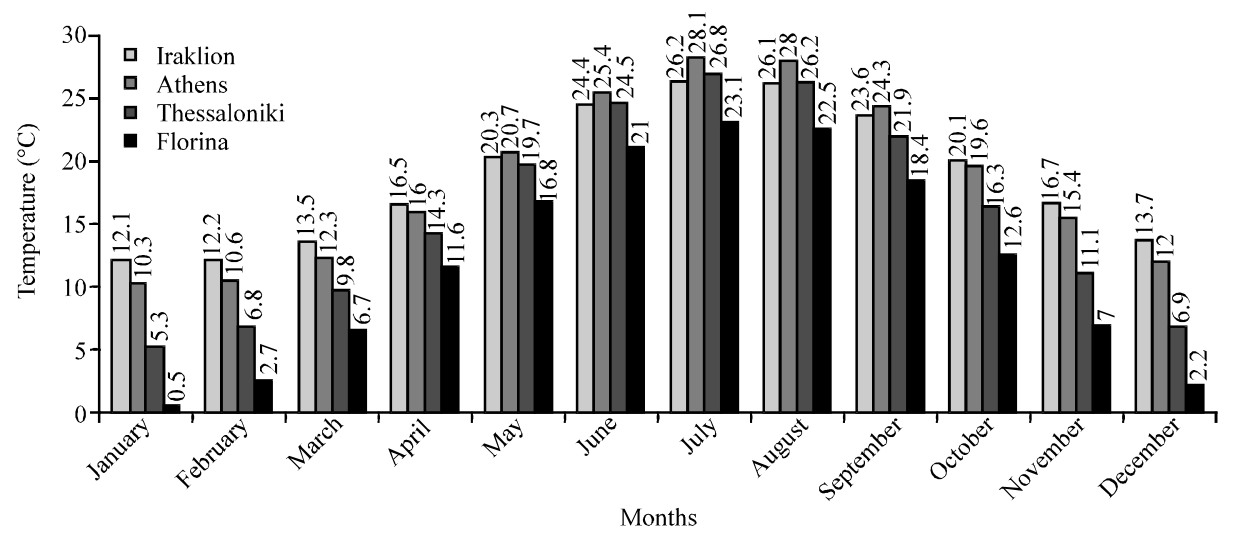

Fig. 2: Monthly variation of air temperature in for 4 cities 
Res. J. Applied Sci., 7 (3): 138-145, 2012

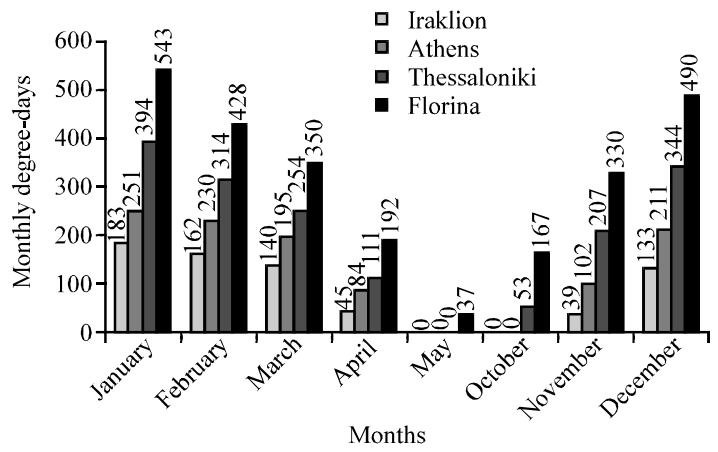

Fig. 3: Heating degree-days per month for each of the 4 consider cities

\begin{tabular}{lrl}
\multicolumn{2}{l}{ Table 2: Pellet characteristics } \\
\hline Index & Values & Norms according to DN 51731 \\
\hline Humidity (\%) & 3.510 & $<12$ \\
Ash (\%) & 0.390 & $<1.5$ \\
Sulphur (\%) & 0.006 & $<0.08$ \\
Caloricity (kJ kg ${ }^{-1}$ ) & 19151.000 & $17500-19500$ \\
\hline
\end{tabular}

because of the increased transportation costs while Athens, Thessaloniki and Florina has similar prices, 0.944 , 0.943 and $0.942 € \mathrm{~L}^{-1}$, respectively. Heating with gas in Greece is available only for some urban areas with fixed price $20 \%$ lower than the heating oil. For these reasons it isn't a good alternative solution.

The biomass boiler costs approximately $2500 €$ and according to the constructor has a life time 15-20 years. Boiler has low annual costs (approximately $50 €$ every year) and requires $300 €$ for an intensive, 10 year period service. The biomass boiler has small electricity consumption (about $100 \mathrm{kWh}$ each year) and this consumption can safely disregard from the financial calculations. The project life is set at 15 years which is an estimation of the burner's life cycle. The pellet price in Greece is around of $225 €$ tons $^{-1}$. In the present study, pellet produced by Technowood Company is considered. The most important characteristics of pellet according to the DIN 51731 certificate are shown in Table 2 . In the financial calculation in the present study there isn't a penalty for the emission of Green House Gases (GHG's).

\section{RESULTS AND DISCUSSION}

Given the meteorological data at a certain site, the RETScreen calculates the pre-tax Internal Rate of Return (IRR) on assets (\%), the simple and equity payback periods (years) and the GHG emission reduction. IRR represents the true interest yield provided by the project assets over its life before income tax, simple payback

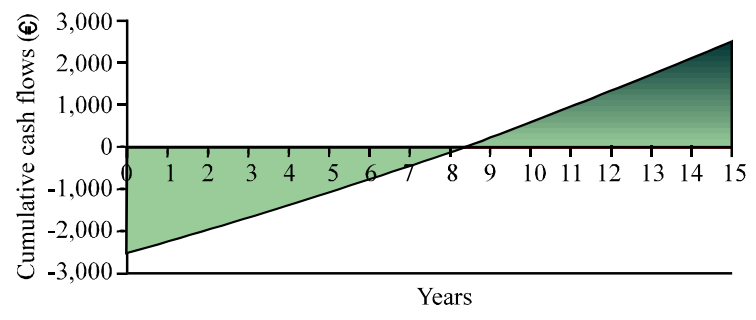

Fig. 4: Cumulative cash flow analysis result for Iraklion

period represents the length of time that it takes for a proposed project to recoup its own initial cost, out of the income or savings it generates and equity period represents the length of time that it takes for the owner of a project to recoup its own initial investment out of the project cash flows generated.

Iraklion evaluation: Iraklion has the lowest heating DD and as expected the annual diesel consumption in the considered building was the lowest of the four cities at just $814 \mathrm{~L}$ of diesel or equally 1.7 tonsof pellet. The cumulative cash flow analysis result, produced by RETScreen for the Iraklion is shown in Fig. 4. The calculated pre-tax IRR for assets is $9.4 \%$. The simple and equity payback periods are 9.6 and 8.3 years, respectively. It is clear from these results that the pellet heating project will not be sufficiently profitable to home owners to encourage them to invest in such a project.

In order to give a general overview of the situation a sensitivity analysis of the effect of diesel and pellet prices on the equity payback period were also conducted. In the present case, thirteen discrete values for diesel price $(0.678,0.728,0.778,0.828,0.878,0.928,0.978,1.028,1.078$, $1.128,1.178,1.228$ and $1.278 € \mathrm{~L}^{-1}$ ) and ten for pellet price $\left(175,200,225,250,275,300,325,350,375\right.$ and $400 €$ tons $\left.^{-1}\right)$ were used in the sensitivity analysis (Fig. 5). From Fig. 5, it becomes clear that the lack of biomass boilers in Crete is absolutely justifiable. About 2 years ago the heating diesel price in Crete was around of $0.60 € \mathrm{~L}^{-1}$ so the biomass solution was not financially sound.

Athens evaluation: Athens is located in the second climatic zone and therefore has slightly higher annual heating DD from the Iraklion. The yearly diesel consumption according to the RETScreen calculation is approximately $946 \mathrm{~L}$ diesel or 1.9 tons of pellet. The cumulative cash flow graph is shown in Fig. 6. The estimated pre-tax IRR value is $18.3 \%$ while the simple and equity payback periods are 5.9 and 5.4 years, correspondingly. The above results indicate that in climatic Zone $\mathrm{B}$ there are advantages from using biofuels instead of heating oil. Sensitivity analysis (Fig. 7) which 
Res. J. Applied Sci., 7 (3): 138-145, 2012

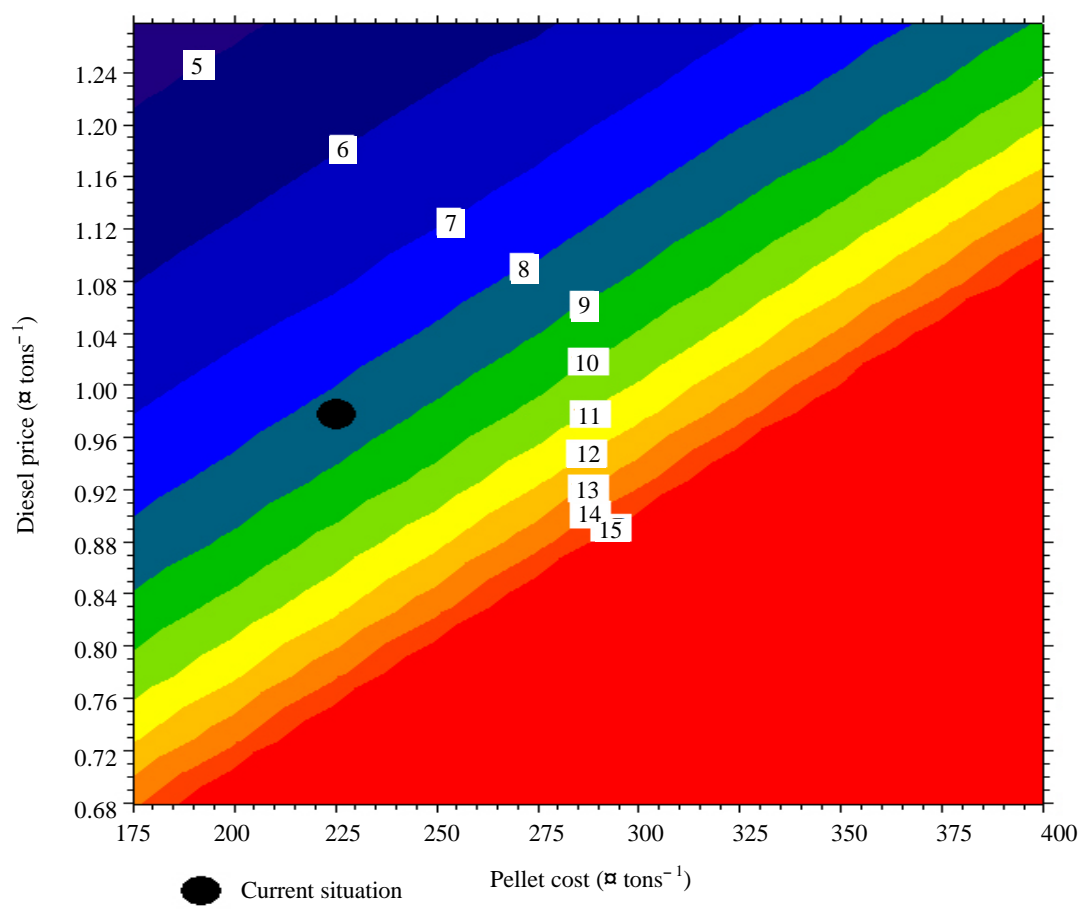

Fig. 5: Sensitivity of diesel price to pellet cost for Iraklion

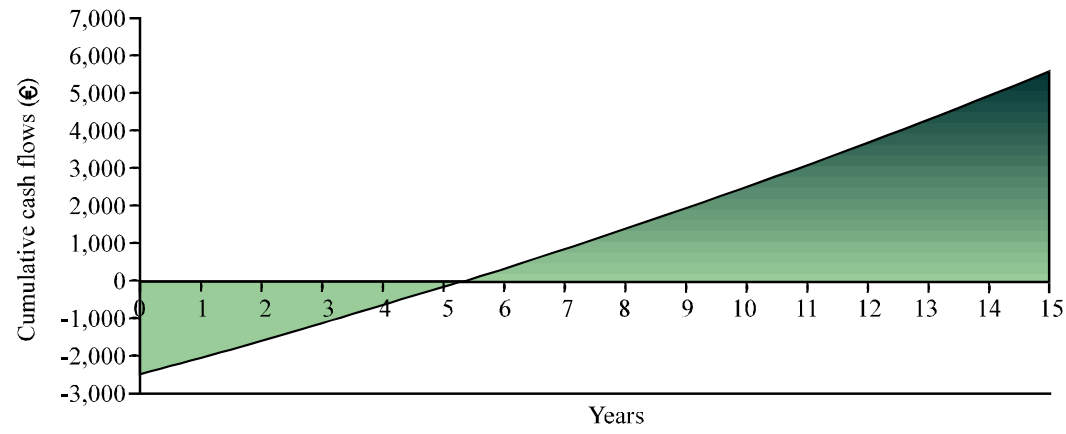

Fig. 6: Cumulative cash flow analysis result for Athens

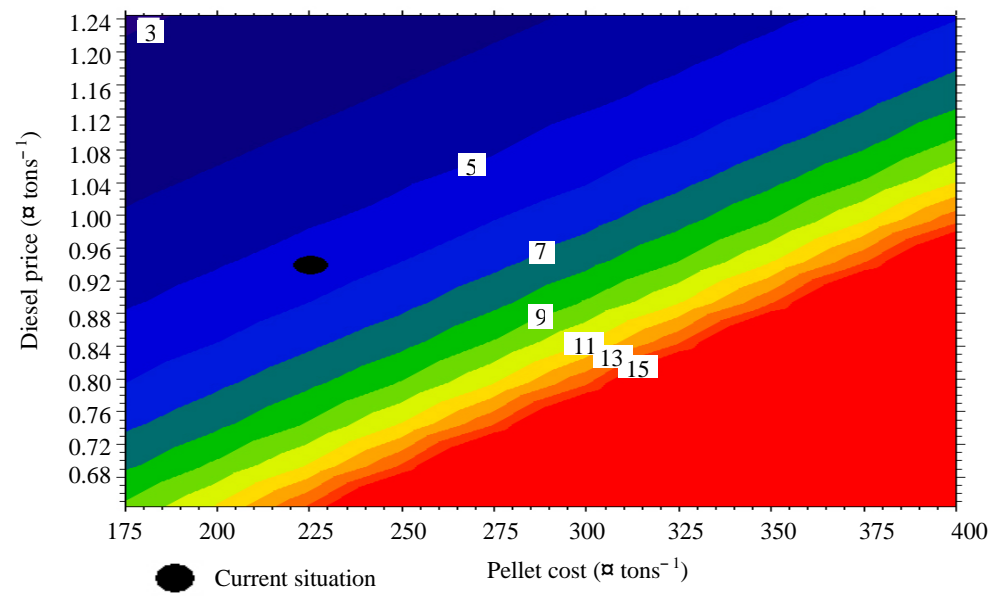

Fig. 7: Sensitivity of diesel cost to pellet price for Athens 
was realized for thirteen discrete values for diesel price $(0.644,0.694,0.744,0.794,0.844,0.894,0.944,0.994,1.044$, $1.084,1.134,1.194$ and $1.244 € \mathrm{~L}^{-1}$ ) and for ten discrete values for pellet price $(175,200,225,250,275,300,325,350$, 375 and $400 €$ tons $^{-1}$ ) gives a better view of the new situations. With diesel price bellow than $0.7 € \mathrm{~L}^{-1}$ the pellet isn't a competitive alternator solution. However, today the heating cost with pellet is about of $50 \%$ less than diesel and the payback period is not last long.

Thessaloniki evaluation: In areas which are placed in the climatic Zone $\mathrm{C}$ there are few biomass boilers mainly in the agricultural districts. Thessaloniki has more than twice heating DD from the Iraklion in 1677 and for this reason a typical building requires almost the double amount of fuel.
Simulation with the RETScreen was shown that the IRR value is $33 \%$ while the simple and equity payback periods are 3.4 and 3.2 years, respectively. The cumulative cash flow graph is shown in Fig. 8. From Fig. 8 it becomes clear that the heating with pellet is financially sound. Figure 9 exhibits the sensitivity analysis in term of heating diesel price and the pellet cost. In the present case, diesel price $(0.643,0.693,0.743,0.793,0.843,0.893,0.943,0.993$, $1.043,1.083,1.133,1.193$ and $\left.1.243 € \mathrm{~L}^{-1}\right)$ and pellet price $\left(175,200,225,250,275,300,325,350,375\right.$ and $400 €$ tons $\left.^{-1}\right)$ were used as sensitivity variables. With the new financial data in Greece even if a unlikely future raise of $70 \%$ in the pellet price occurs in the next months the wood pellets to be a cost-effective alternative heating fuel when compared to diesel. Only in improbable case in which the diesel price

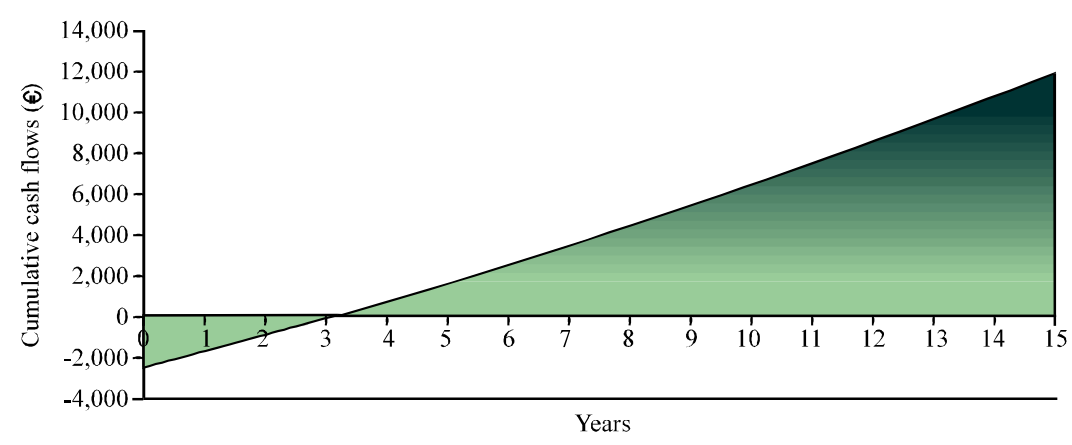

Fig. 8: Cumulative cash flow analysis result for Thessaloniki

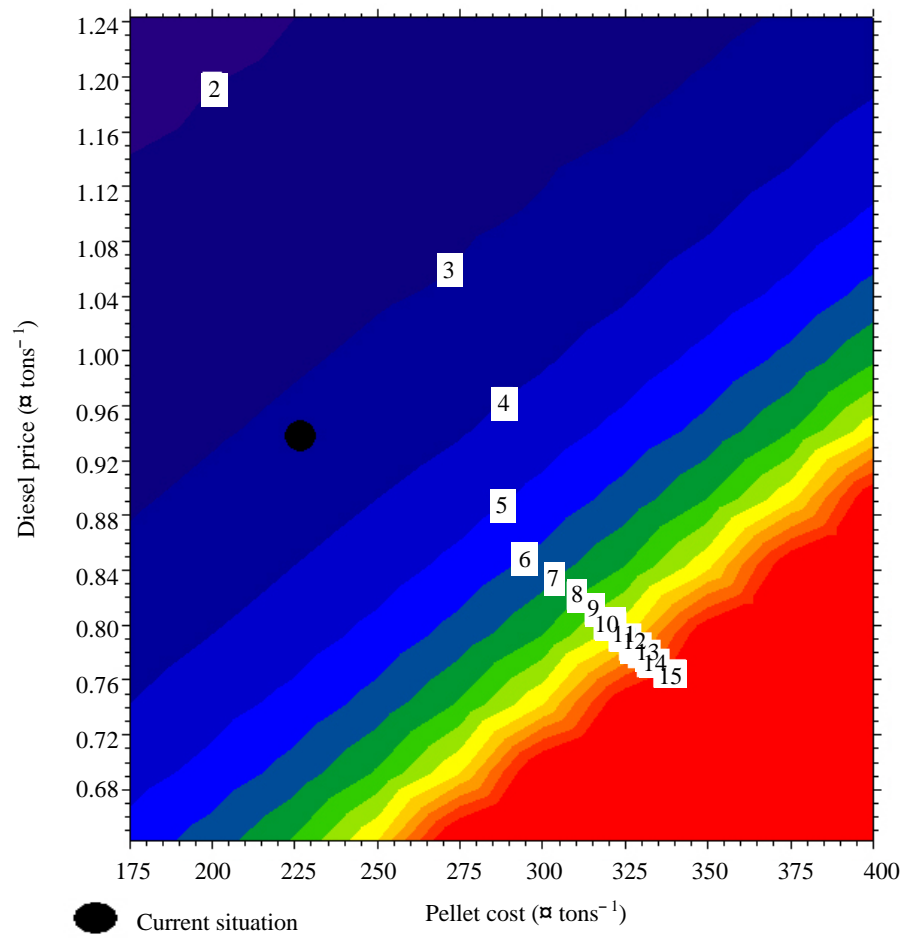

Fig. 9: Sensitivity of diesel price to pellet cost for Thessaloniki 
decreases $>30 \%$ and the same time the pellet price increases $>15 \%$ the heating diesel will be again a feasible solution. In the areas which are positioned in the climatic Zone $\mathrm{C}$ there are the biggest interests from the building owners in order to replace the fossil fuel boilers with biomass boilers.

Florina evaluation: In the climatic Zone $\mathrm{D}$, there are the more biomass boilers in Greece. However, in the residential areas are rather infrequent. Florina is the champion in Greece in the snowfalls. A typical building $90 \mathrm{~m}^{2}$ requires for space heating $>2.5$ tons diesel or 5 tons pellet. According to the RETScreen calculations, the estimated pre-tax IRR value is $51.5 \%$. The simple and equity payback periods are just 2.1 and 2 years, correspondingly. The cumulative cash flow graph is shown in Fig. 10. Without doubts the heating with biomass is the only solution. The sensitivity analysis (Fig. 11) shows that the regression to the diesel today seems like an improbability.

Environmental benefits: Replacing heating generated by fossil fuels boilers with biomass such as pellet could provide further benefits to Greece in the form of reduced emissions of priority air pollutants and GHG as the pellet is a clean-burning renewable fuel source. The RETScreen Software is capable of estimating the amount of GHG which could be avoided as a result of usage of biomass

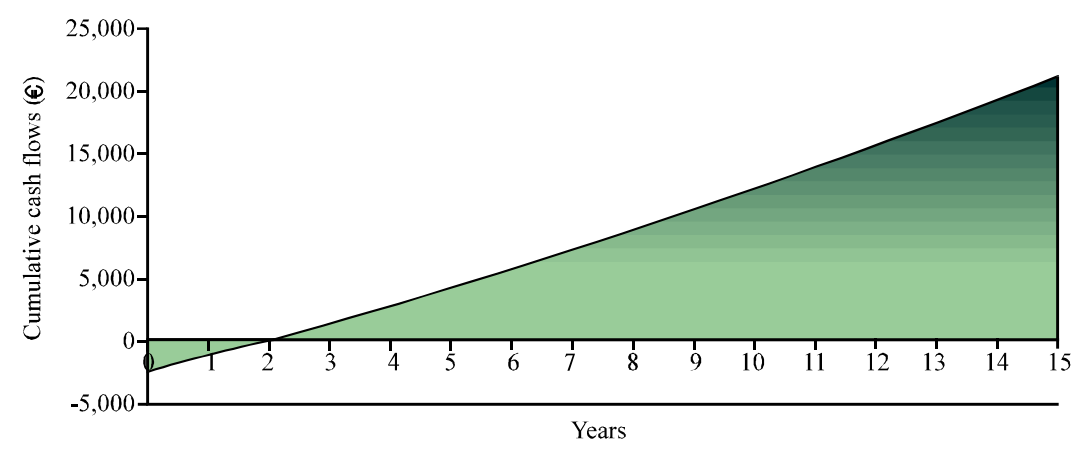

Fig. 10: Cumulative cash flow analysis result for Florina

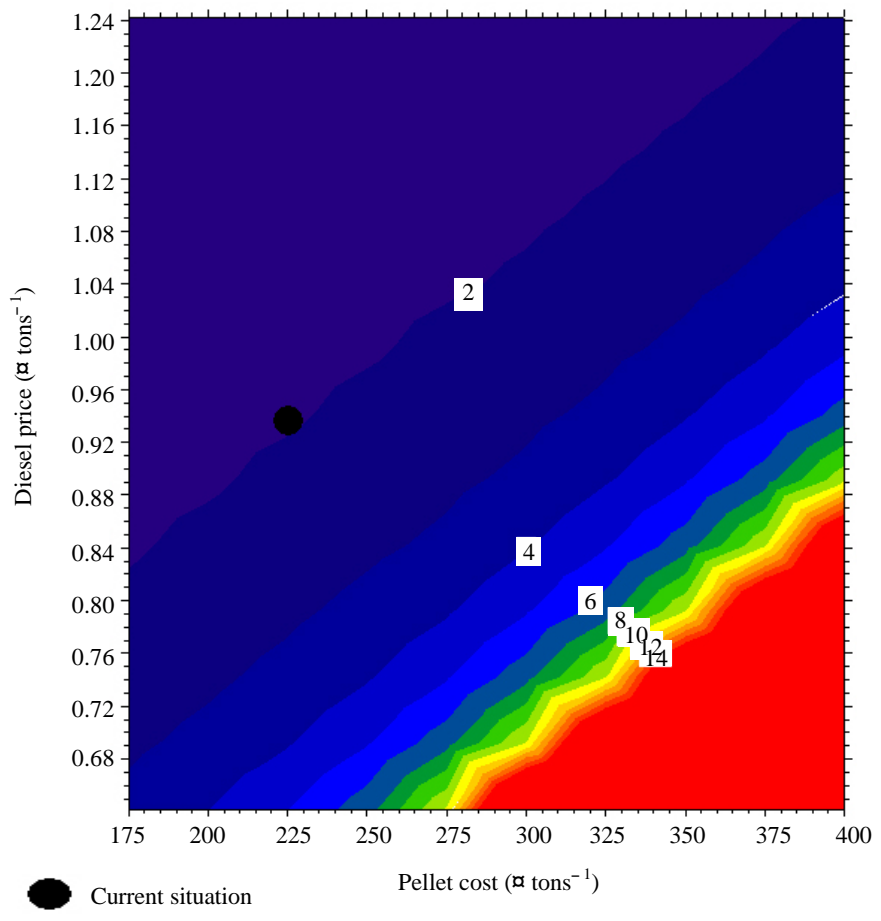

Fig. 11: Sensitivity of diesel price to pellet cost for Florina 


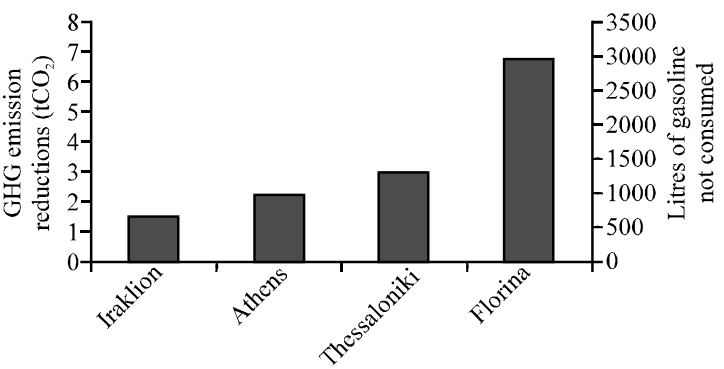

Fig. 12: Green house gases reduction due usage of pellet boilers

boilers. The amount of GHG reduction and the equivalent in litres of gasoline that not consumed for the 4 locations are shown in Fig. 12. As expected the highest GHG emissions mitigation of 6.7 tons year $^{-1}$ was observed at Florina and the lowest reduction was observed at Iraklion with a value of 1.5 tons year ${ }^{-1}$.

\section{CONCLUSION}

The financial crisis and the expensive diesel oil are pushing the Greek citizens to the biomass. With this paradox way and not for environmental reasons, wood pellet heating boilers remove the traditional oil heating devices. At the same time, the crisis in Greece indicate that is unlikely that any future carbon or energy taxes will increase the cost of biomass fuels and are more likely to raise the cost of heating with fossil fuels. Considering that oil prices are continuously increasing, a future raise in the price of heating oil is the most probable scenario which will encourage inhabitants to invest in bio fuels. In accordance with the financial results the conclusions which arise from the present study can be summarised as follows:

- In the climatic Zone A the heating requirements are low and the biomass project is a marginal profitable investment

- In the climatic Zone B with the new taxes wood pellet is a good choice for heating

- In the third climatic zone pellet heating is by far more cost-saver than fossil fuel heating systems

- In the climatic Zone D the financial crisis has made the biomass heating a solution that defies the competition

\section{ACKNOWLEDGEMENT}

The researchers are thankful to Mr. N. Papadopoulos, managing director on Thokas company for his comments and helpful discussions. The present research is a research result that became in the frames of operational programme Competitiveness and Entrepreneurship (OPCE II-) of the Hellenic Republic of Ministry of Development for the period 2007-2013, co-financed by the European Union (NSRF) European Regional Development Fund for the project with title: Monitoring System for abiotics and biotics factors, affecting the changes of climate territorial forestries and agriculturals lands Valasia.

\section{REFERENCES}

ASHRAE, 2005. ASHRAE Handbook Fundamentals: Chapter 29 Residential Cooling and Heating Load Calculations. American Society of Heating Refrigeration and Air-Conditioning Engineering, Atlanta, Georgia.

EurObserv'ER, 2011. Solid biomass barometer. EurObserv'ER, November 2011. http://www. eurobserv-er.org/pdf/biomasse_2011.pdf.

Mediavilla, I., M.J. Fernandez and L.S. Esteban, 2009. Optimization of pelletisation and combustion in a boiler of $17.5 \mathrm{kWth}$ for vine shoots and industrial cork residue. Fuel Process. Technol., 90: $621-628$.

RETScreen International, 2005. Clean Energy Project Analysis: RETScreen ${ }^{\text {( }}$ Engineering and Cases Textbook. 3rd Edn., Minister of Natural Resources, Canada, ISBN: 0-662-39191-8, Pages: 456.

RETScreen International, 2010. Renewable energy project analysis software. RETScreen International, Varennes, Canada. http://sdo.ew.eea.europa.eu/tools/ retscreen-international-renewable-energy-project.

Technical Chamber of Greece, 2010. Climatic data on Greece. First Edition, T.O.T.E.E. 20701-3/2010. http:/www. energynius.gr/files 4users/files/TOTEE20701-3-Final-TEE.pdf (In Greek).

Verma, V.K., S. Bram, I. Vandendael, P. Laha, A. Hubin and J. De Ruyck, 2011. Residential pellet boilers in Belgium: Standard laboratory and real life performance with respect to European standard and quality labels. Applied Energy, 88: 2628-2634.

Wiinikka, H. and R. Gebart, 2004. Experimental investigations of the influence from different operating conditions on the particle emissions from a small-scale pellets combustor. Biomass Bioenergy, 27: 645-652. 